\title{
CONTRIBUTOS PARA UMA REFLEXÃO SOBRE ALGUMAS LEITURAS DO PROCESSO DE MODERNIZAÇÃO DA SOCIEDADE PORTUGUESA CONTEMPORÂNEA*
}

\begin{abstract}
António Rafael Amaro**
Neste artigo, procuraremos fazer uma reflexão sobre as leituras que têm sido feitas sobre o nosso processo de modernização económica. Destacando os períodos da nossa história em que Portugal divergiu e se atrasou, relativamente aos paises mais ricos, mas, também, aqueles em que convergiu e se aproximou. Problematizaremos, ainda, a forma como a magna questão do nosso atraso económico tem sido tratada na literatura da especialidade, pondo em confronto as duas principais correntes.
\end{abstract}

\section{INTRODUÇÃO}

Não temos outra pretensão com este artigo que não seja a de contribuir para uma pequena reflexão sobre as leituras que têm sido feitas do processo de modernização da sociedade portuguesa e, deste modo, se possível, colaborar na construção de um conhecimento menos mistificador do lugar que Portugal ocupa no sistema mundial. Queremos, com isso, dizer que este trabalho não utiliza dados empíricos originais sobre esta problemática; limitámo-nos a dialogar com aquilo que vem sendo produzido sobre esta temática, utilizando intencionalmente conclusões e estudos bastante diferentes, em termos metodológicos, epistemológicos e, naturalmente, ideológicos.

\footnotetext{
** Instituto Universitário de Desenvolvimento e Promoção Social - Pólo de Viseu do Centro Regional das Beiras da Universidade Católica Portuguesa.
} 
É inegável que as diversas ciências sociais, sobretudo nas duas últimas décadas, têm dado passos importantes para uma melhor compreensão das transformações ocorridas na sociedade portuguesa e para uma ideia bem mais clara do nosso desenvolvimento. Não obstante, as interpretações sobre questões tão importantes como aquelas que se ligam com o nosso atraso económico - e até mesmo sobre o nosso peso e lugar no contexto da economia-mundo -, estão longe de poderem ser feitas numa base de amplo consenso.

Porém, o que preocupa não é tanto a falta de consenso - aliás, porventura, não desejável - entre as diversas correntes de pensamento, mas o facto de neste domínio, como aliás noutros, tardar a tornar-se senso comum muito do conhecimento produzido mais recentemente. Ou seja: o que faz pouco sentido é ainda dominarem, no senso comum e mesmo na denominada comunicação de massas, interpretações e discursos excessivamente míticos, com escassa base empírica, que, por norma, tão depressa produzem um discurso deslumbrado, como logo abraçam visões temperadas pelo negativismo. Gosta de recordar, a este propósito, o sociólogo Boaventura Sousa Santos (1991: 63) que muito deste discurso inscreve-se, consciente ou inconscientemente, numa visão mítica de «que Portugal tem um destino, uma razão teológica que ainda não cumpriu ou que só cumpriu no período áureo dos descobrimentos». Este facto leva-o, naturalmente, a ler o presente como um período de decadência e, mesmo quando projecta uma ideia positiva do país, fá-lo de «modo elitista e desfocado», quase sempre «à beira da frustração, da queda $\mathrm{e}$ do ressentimento»".

Parece-nos evidente, por isso, que a persistência deste relativo desconhecimento sobre nós mesmos e o excesso de pensamento mítico encontra explicação em dois factos principais: por um lado, as ciências sociais sofreram durante o Estado Novo enormes constrangimentos, em que a falta de liberdade e a inexistência de uma tradição filosófica e científica crítica e aberta não foram por certo os menos importantes ${ }^{2}$. Este contexto político, aliado ao factor social de país semiperiférico, com tudo o que isso implica em termos económicos e culturais, levou a que as diversas ciências sociais não beneficiassem das transformações epistemológicas e metodológicas que, entretanto, se iam verificando nos países mais desenvolvidos. A comprová-lo, como lembra o autor referido anteriormente, está o facto de os primeiros e mais importantes estudos sociológicos empíricos, sobre a sociedade portuguesa, terem sido realizados por sociólogos estrangeiros. Acrescentando, com ironia, que a relutância era tanta, por parte do Estado Novo, em relação à sociologia que não raro era confundida com socialismo ${ }^{3}$; por outro lado, são bem conhecidas as queixas generalizadas dos investigadores pelo facto de muitos dos contributos trazidos pelas ciências sociais nas últimas décadas 
continuarem a encontrar barreiras na sua divulgação e discussão, nomeadamente fora dos estritos circuitos académicos e científicos. Dificuldades de divulgação que esbarram, quase sempre, em muitas características da sociedade actual: cada vez mais se confunde informação com conhecimento, prevalecendo a ditadura da temporalidade mediática que, como é sabido, não se presta muito às exigências e características habituais do conhecimento científico; por norma, este é «mais analítico do que normativo, mais parcelar do que global, com maiores preocupações de rigor teórico e metodológico do que com a espectacularidade das conclusões, com menos certezas do que alguns desejariam». ${ }^{4}$

Assim, parece-nos importante fazer, à luz dos conhecimentos científicos mais recentes, como que um balanço do comportamento económico do Portugal contemporâneo, abordando sem complexos aquilo que ainda nos separa, em termos de desenvolvimento, dos países mais avançados. É necessário ter presente que, seja qual for o contexto, dificilmente qualquer reflexão, sobre as transformações estruturais da sociedade portuguesa contemporânea, poderá evitar aquilo que alguns autores chamam a «relação da sociedade portuguesa com a modernidade. E, de maneira muito especial, com a modernidade avançada (alguns chamar-lhe-ão pós-modernidade)» ${ }^{5}$. Ou seja: independentemente do modo como problematizamos o sentido modernizador da sociedade portuguesa, seja de forma mais explícita ou implícita, dificilmente poderemos deixar de formular, entre outras, as seguintes questões: Portugal é um país modernizado, desenvolvido, ou nem por isso? Portugal está a convergir e desde quando com os países mais evoluídos? Portugal fracassou, fez o que estava ao seu alcance? O nosso atraso ficou a dever-se às más políticas, à nossa dependência externa, ou à nossa debilidade a nivel de recursos endógenos?

Estas e outras questões, como é evidente, carregam sempre modelos de comparação e, em última análise, têm subjacente uma ideologia, uma maneira de ver o mundo, uma determinada leitura do real social. E há mesmo quem avance - questão que desenvolveremos mais adiante -, que o facto de Portugal ser um país de desenvolvimento intermédio tem dificultado o seu estudo por ausência de adequados instrumentos teóricos, normalmente importados, mais preparados para analisar sociedades desenvolvidas ou subdesenvolvidas. Esta situação leva, como adverte Boaventura Sousa Santos, a que muitos investigadores não tenham em conta esta especificidade e estudem o nosso país por comparação negativa, privilegiando nas suas análises aquilo que ele não tem. Ora, para este sociólogo, «tal negatividade é uma outra forma de desconhecimento e por isso também campo fértil de análises míticas»"

Curiosamente (ou talvez não), este excesso mítico parece não ser apenas apanágio do nosso país. Félix Ortega, no seu livro El Mito de la 
Modernización, faz o seguinte retrato da sociedade espanhola, que bem podia aplicar-se ao nosso país:

«A plena modernização da sociedade [Espanhola] faz-se tardiamente, a um ritmo mais acelerado que noutros lugares, resultando difícil a assimilação das transformações. De maneira que, envolvida nas convulsões e orientações encontradas, a sociedade viveu a cavalo entre dois mitos, ambos igualmente ilusórios: o do passado glorioso, emblemático de todos os conservadorismos triunfantes, e o da modernidade por vir, lema animador de quantos movimentos progressistas têm surgido entre nós». ${ }^{7}$

Referimos já anteriormente que uma questão que sempre incomodou os portugueses, agora com novos condimentos, sobretudo num tempo em que se tornou central, mesmo no debate político, o problema da nossa convergência/divergência económica com a média da União Europeia, foi o nosso atraso económico. A esta questão central, por sua vez, ligam-se duas outras (não menos importantes e que, de certa forma, a ajudam a entender) que, normalmente, aparecem assim formuladas:

a) Portugal encontra-se hoje, em termos de desenvolvimento económico e do papel a desempenhar no contexto da economia-mundo, mais perto ou mais longe dos países desenvolvidos e/ou centrais?

b) Caso tivessem sido outras as políticas de desenvolvimento seguidas, em diversos períodos da nossa história e tendo em conta o nosso potencial económico endógeno, poderia Portugal ter feito melhor e encontrar-se hoje no pelotão da frente dos países centrais?

Felizmente, para todos os que se interessam por estas questões do desenvolvimento, é hoje possível, com base em estudos comparativos internacionais e, sobretudo, em trabalhọs sobre a economia nacional, responder com alguma segurança (isto não significa unanimismo nas respostas) às questões anteriormente formuladas.

\section{A POSIÇÃO DE PORTUGAL NO SISTEMA MUNDIAL}

Em relação à questão formulada na alínea a), e sem querer ser simplista, diria que Portugal afinal está onde sempre esteve; o que poderá parecer pouco aos mais exigentes, mas, por outro lado, se tivermos em conta a descolagem tardia do nosso país, como veremos adiante, também não permite discursos derrotistas do género daqueles que vaticinam que Portugal está condenado a ficar na cauda das economias da Europa. Ou seja: se fizermos uma leitura global e tivermos subjacente a teoria de economia-mundo desenvolvida por Immanuel Wallerstein ${ }^{8}$ - esta teoria, nas palavras de Boaventura Sousa 
Santos, que em Portugal a tem utilizado de forma sistemática em diversos trabalhos sobre a sociedade portuguesa ${ }^{9}$, «privilegia o estudo das dinâmicas globais e das temporalidades longas e médias em detrimento das especificidades sociológicas e das historicidades próprias das diferentes sociedades que compõem o sistema mundial» -, pode dizer-se que Portugal, pelo menos desde o século XVIII até hoje, sempre se posicionou internacionalmente como um país semiperiférico de desenvolvimento intermédio, com tudo o que isso implica em termos económicos, políticos, sociais, etc. ${ }^{10}$. Isto não significa, como veremos também mais adiante, que durante os dois últimos séculos, por exemplo, Portugal não tivesse períodos em que se atrasou economicamente, se tivermos em conta um indicador como o PIB per capita, e outros em que convergiu; contudo, mantivemos até hoje, naquilo que é essencial em termos de desenvolvimento, determinadas características estruturantes, no quadro da economia-mundo, de país semiperiférico. Com efeito, Portugal, devido exactamente ao seu carácter intermédio, «desempenhou uma função de intermediação entre o centro e a periferia do sistema mundial e um pouco como as classes médias o fazem nas sociedades nacionais, contribuiu para atenuar os conflitos e as tensões entre $o$ centro e a periferia» (Santos, 1993: 22). Ora, Portugal foi, pelo menos até 1974, não há dúvidas sobre isso, simultaneamente centro e periferia: centro em relação ao império colonial e periferia em relação à Europa ${ }^{11}$. Esta qualidade de intermediação, que não é apenas económica e que aparece bem ilustrada em vários momentos da nossa história, nas relações que mantivemos com as nossas colónias e com a Inglaterra, não só aparece como específica da história da Europa, como é também parte integrante do processo de desenvolvimento e modernização económica do nosso país, enquanto país europeu (Santos, 1993: 23). Talvez esta aparente singularidade da nossa história, simultaneamente centro e periferia, com importante papel de intermediação entre pobres e ricos, ajude a explicar a leitura que dela faz António José Telo (1997: 651) que, contestando as interpretações dependentistas, mostra preferência pelo conceito psicofisiológico de «disfunção» ${ }^{12}$, para explicação daquilo que algumas vezes nos é específico. Penso ser esta posição, de intermediação mantida pela sociedade portuguesa, que ajuda a explicar não só um sintoma permanente de aparente «disfunção», como até o nosso singular percurso histórico: «É a realidade de um país que sistematicamente, nos mais diversos sistemas internacionais, nas mais variadas conjunturas, orientado pelos dirigentes das mais caleidoscópicas cores políticas e múltiplas capacidades, consegue normalmente desempenhar um papel e realizar funções que estão acima da sua força aparente» (Telo, 1997: 651).

O fim do Império Colonial, as transformações operadas com o 25 de Abril de 1974 , que aceleraram mudanças importantes no sentido da modernização 
na nossa sociedade e a integração de Portugal na CEE, actualmente União Europeia, parecem não ter modificado no essencial o estatuto de desenvolvimento intermédio conferido à sociedade portuguesa ${ }^{13}$. É verdade que alguns autores (Mateus, 1998: 17), tendo em conta que Portugal, nos inícios da década de 90, ultrapassou o limiar do PIB per capita (9 500 dólares) - degrau normalmente considerado pelo Banco Mundial para se aceder ao estatuto de país desenvolvido -, registam este facto para defenderem que Portugal entrou no clube dos países desenvolvidos. Pode ainda acrescentar-se, a este indicador, um outro mais rico (para além do PIB per capita, inclui a esperança de vida à nascença, taxa de alfabetização de adultos, taxa de escolaridade bruta, índice de educação), desenvolvido, desde 1990, pelo Programa das Nações Unidas para o Desenvolvimento (PNUD), que coloca o nosso país, com resultados de 1995 e publicados em 1998, em $33^{\circ}$ lugar num ranking de 174 países, a uma curta distância daquilo que esta organização considera como desenvolvimento humano elevado (DHE) e bastante longe do que é reconhecido como desenvolvimento humano médio (DHM) ${ }^{14}$. Contudo, para os autores que temos vindo a seguir (Santos, Reis, Fortuna, 1993), as inegáveis transformações estruturais, verificadas neste século - sobretudo, desde 1960, com acelerações várias nas últimas duas décadas (Cf. Quadros ns 1 a 3) -, alteraram substancialmente a configuração do país, mas não modificaram, naquilo que é estruturante na nossa sociedade, o seu lugar no quadro do sistema mundial, mantendo-se o nosso país semiperiférico e, em termos dos indicadores socioeconómicos mais relevantes, de desenvolvimento intermédio. Tal facto, aliás, se isso nos conforta, é comum a outros nossos parceiros na União Europeia, como a Irlanda, a Grécia e Espanha, embora esta cada vez menos (Santos, 1991: 61). 
Contributos para uma reflexão sobre algumas leituras do processo de modernização da sociedade portuguesa contemporânea

\section{Quadro n⿳1}

DISTRIBUIÇÃO SECTORIAL DA POPULAÇÃO ACTIVA (PERCENTAGENS)

\begin{tabular}{l|c|c|c|c|c|c}
\hline & $\begin{array}{c}1890 \\
(1)\end{array}$ & $\begin{array}{c}1950 \\
(2)\end{array}$ & $\begin{array}{c}1960 \\
(3)\end{array}$ & $\begin{array}{c}1974 \\
(4)\end{array}$ & $\begin{array}{c}1982 \\
(5)\end{array}$ & $\begin{array}{c}1992 \\
(6)\end{array}$ \\
\cline { 2 - 7 } Sector Primário................. & 60 & 50 & 44,4 & 35,5 & 25,9 & 11,8 \\
\cline { 2 - 7 } Sector Secundário............ & 20 & 26 & 28,1 & 32,3 & 36,8 & 32,6 \\
\cline { 2 - 7 } & 20 & 24 & 27,5 & 32,2 & 37,3 & 55,6 \\
\hline
\end{tabular}

Fontes: 1 a 3 Mata e Valério (1993); 4 a 6 Barreto (1996).

\section{Quadro n' 2 \\ COMPOSIÇÃO SECTORIAL DO PIB \\ (PREÇOS CORRENTES - PERCENTAGENS)}

\begin{tabular}{l|c|c|c|c|c}
\hline & $1928-1939$ & 1960 & 1976 & 1977 & 1990 \\
& $(1)$ & $(2)$ & $(3)$ & $(4)$ & $(5)$ \\
\cline { 2 - 6 } Sector Primário............... & 33,0 & 25,9 & 15,1 & 12,3 & 5,8 \\
Sector Secundário............ & 26,0 & 36,4 & 42,3 & 36,3 & 38,2 \\
Sector terciário.............. & 41,0 & 37,6 & 42,6 & 51,4 & 55,9 \\
\hline
\end{tabular}

Fontes: I Mateus (1989); 2 a 5 Barreto (1996).

\section{Quadro $\mathbf{n}^{\mathbf{3}} 3$}

ESTATÍSTICAS DEMOGRÁFICAS: QUADRO-RESUMO-SÉCULO XX

\begin{tabular}{|c|c|c|c|c|c|c|c|}
\hline & 911 & 1920 & 1930 & 1940 & 1960 & 1970 & 1991 \\
\hline $\begin{array}{l}\text { Taxa de mortalidade } \\
\text { infantil (perm.)................... }\end{array}$ & & 176,5 & 143,6 & 126,1 & 77,5 & 55,5 & 10,8 \\
\hline $\begin{array}{l}\text { Esperança de vida à } \\
\text { nascenç }(\mathrm{H} \text { anos }) . . . \ldots \ldots \ldots . . .\end{array}$ & & 35,8 & 44,8 & 48,6 & 60.7 & 64,2 & 70,3 \\
\hline $\begin{array}{l}\text { Esperança de Vida à } \\
\text { nascença }(M \text { Anos).............. }\end{array}$ & & 40,0 & 49,2 & 52,8 & 66,4 & 70,8 & 77,5 \\
\hline $\begin{array}{l}\text { Pop. residente em aglomera- } \\
\text { dos com mais de } 10000\end{array}$ & & & & & & & \\
\hline $\begin{array}{l}\text { habitantes.................................. } \\
\text { População activa no sector }\end{array}$ & & 16,6 & 18,4 & 19,3 & 22,6 & 26,5 & 33,1 \\
\hline & 57,8 & & 48,9 & 50,7 & 44,4 & 32,1 & 10,1 \\
\hline $\begin{array}{l}\text { Taxa de analfabetismo \%...... } \\
\text { Percentagem de partos em } \\
\text { estabelecimentos de saúde.... }\end{array}$ & 69,2 & 65,4 & 60,4 & 53,6 & $\begin{array}{l}33,1 \\
18,4\end{array}$ & $\begin{array}{l}25,6 \\
37,5\end{array}$ & 11,0 \\
\hline
\end{tabular}

Fonte: Barreto (1996). 
O facto de sermos um país de desenvolvimento intermédio ajuda a explicar a nossa modernização bastante heterogénea e espacialmente muito desigual. É, por isso, possível encontrar indicadores que se identificam claramente com o padrão dos países centrais (taxas de natalidade, fecundidade, envelhecimento, leis e instituições, valor da taxa de actividade feminina, mesmo algumas práticas de consumo), ao lado daquilo que alguns autores (Machado e Costa, 1998: 17-44) denominam de «Processo de Modernidade Inacabada»: por exemplo, o baixo nível das qualificações escolares e profissionais, a taxa de analfabetismo, as formas extensas de velhas e novas formas de exclusão social, os desequilíbrios regionais, com uma progressiva litoralização da nossa modernização económica, sempre acompanhada pelo crescente despovoamento do interior.

Temos assim um país, que podíamos dizer a várias velocidades, onde coexistem, sem necessidade de percorrer largas distâncias, níveis de desenvolvimento próprios da pré-modernidade, modernidade e pós-modernidade. Esta singularidade da sociedade portuguesa que, muitas vezes, escapa aos indicadores sociais tradicionais e que tem vindo a ser evidenciada em diversos trabalhos desenvolvidos pelo Centro de Estudos Sociais da Faculdade de Economia da Universidade de Coimbra, coordenados por Boaventura Sousa Santos, pode resumir-se do seguinte modo:

a) O nosso modelo de desenvolvimento agrícola, ao contrário da maioria dos nossos parceiros europeus, não foi acompanhado de um rápido e intensivo êxodo dos campos, permanecendo a pequena agricultura familiar por modernizar (por exemplo, fraca mecanização, deficiente gestão e comercialização) e, por via disso, assistimos à continuação persistente de hábitọs seculares de auto-consumo ou produção mercantil simples. Este modelo de desenvolvimento explica, certamente, a situação de Portugal continuar a deter a mais elevada percentagem de população a viver em meio rural. Como aliado deste modelo, é também característica da nossa sociedade a denominada pluriactividade, que permite aos operários, em muitas regiões do país, obterem rendimentos compostos, a um tempo, do trabalho industrial e, a outro, da agricultura. Realidade social com implicações várias (políticas, simbólicas, formas de sociabilidade, etc.) e que, sendo estruturante na sociedade portuguesa ${ }^{15}$, tem consequências económicas e sociais no mínimo contraditórias: por um lado, «a pequena agricultura, sem dúvida uma componente estruturante do processo de industrialização», funciona, muitas vezes, "como um importante mecanismo de compensação em períodos de crise, mas, por outro, 
tem aliviado a pressão sobre os salários, contribuindo, assim, para a degradação da especialização industrial» (Santos, 1993: 43). Saliente-se, entretanto, que estas características da nossa agricultura, por muitos considerada pré-moderna, podem passar a ser vistas com outros olhos, sobretudo se vingarem modelos alternativos de produção agrícola, mais preocupados com o ambiente e com as pessoas em concreto e menos com o custo unitário do produto. $\mathrm{E}$, neste caso, talvez tivéssemos a possibilidade de queimar etapas (dando o salto de um modelo pré-moderno para um pós-moderno), trocando o modelo produtivista por uma agricultura «mais miúda, de produto mais identificado e personalizado, ao nível local e regional» (Portela, 1998: 7).

b) Outro exemplo, da articulação na nossa sociedade de elementos pré-modernos, modernos e pós-modernos, está bem patente a nível dos cuidados de saúde. Para tanto, basta ver o papel que ainda desempenha no nosso país a denominada medicina popular. Quantas vezes ela ainda é tida como primeira prioridade por muitos portugueses, tanto na sua versão naturalista (chás, endireitas, etc.) e mesmo na sua versão sobrenatural (bruxos(as), promessas, mezinhas, rezas, etc.). Esta realidade leva Boaventura Sousa Santos a concluir o seguinte: «Como quer que seja, a produção de saúde em Portugal é o resultado de uma articulação complexa entre três tipos de produção médica: a medicina oficial estatal, a medicina oficial privada e a medicina popular» (Santos, 1991: 62);

c) Outro domínio onde a modernidade tarda prende-se com a ineficiência da centralidade do Estado. Basta ver o domínio que entre nós ainda têm fenómenos como o populismo e mesmo o clientelismo. Domina ainda na nossa sociedade aquilo que alguns autores (por exemplo, Santos, 1991) denominam de «lógicas societais particularísticas com influência suficiente para orientar a seu favor e de modo não oficial, informal e privado, a actuação do Estado». Em linguagem simples, diríamos que ainda são tolerados, quando não incentivados, fenómenos como dar uma mãozinha para fugir aos impostos, para passar nos diferentes exames, não ir à tropa, conseguir emprego, ganhar questões em tribunal, etc.

d) Questão também muito importante e central na sociedade portuguesa e que pode servir de exemplo do engenho, a que a necessidade obrigou, prende-se com aquilo que, mais uma vez, o sociólogo Boaventura Sousa Santos denominou de «Fraco Estado-Providência e «Forte Sociedade-Providência». Quer isto dizer que, apesar dos esforços feitos, nomeadamente no pós-25 de Abril, 
nunca se constituiu em Portugal um Estado Providência forte e estruturado, como na maior parte dos nossos parceiros europeus. «O Estado português não é - Lembra (Santos, 1993: 43) - um Estado-Providência no sentido próprio do termo, embora em certos aspectos se aproxime dessa forma política», o que acontece é que «o défice da actuação do Estado português enquanto Estado-Providência é parcialmente compensado pela actuação de uma sociedade suficientemente rica em relações de comunidade, interconhecimento e entreajuda, um fenómeno a que chamo sociedade-providência. Para ilustrar este fenómeno - o qual, com base em laços de parentesco e de vizinhança, se caracteriza pela troca de bens e serviços assentes na lógica pré-moderna da reciprocidade não mercantil -, refiram-se três exemplos, entre muitos possíveis: 1) transporte de alimentos, com intenção de ofertar, nas visitas aos doentes nos estabelecimentos de saúde, prática efectuada, muitas vezes, às escondidas dos responsáveis, por não ser permitida; 2) estudo recente (cit. por Santos, 1993: 47) regista que na década de 90, nos dois hospitais centrais de Lisboa, mais de 10 mil pessoas visitam amigos ou familiares aos fins de semana, valores inéditos em qualquer país europeu; 3) cálculos efectuados, para o ano de 1981 , evidenciaram que $71 \%$ dos activos desempregados em Portugal declararam que era no seio familiar que obtinham a principal fonte do seu rendimento e de subsistência, «o que indiscutivelmente demonstra não só o défice de providência estatal (baixos subsídios de desemprego) como também a importância da providência societal, no caso, de âmbito familiar» (Santos, 1993: 47).

Feita esta primeira abordagem, importa agora, para concluirmos a questão proposta na alínea a), analisar a posição relativa de Portugal, com base no crescimento do PIB per capita, relativamente à média dos 15 países que actualmente compõem a União Europeia (UE), tendo em conta os marcos mais significativos, entre 1820 e 1992 (Quadro nº). Optámos, também, por incluir no quadro, para além de Portugal, mais três países: Espanha, Grécia e Irlanda. A intenção é comparar o comportamento económico daqueles com Portugal, por se tratar de países que poderemos também qualificar de desenvolvimento económico intermédio. 
Contributos para uma reflexão sobre algumas leituras do processo de modernização da sociedade portuguesa contemporânea

\section{Quadro n 4}

PORTUGAL: PNB PER CAPITA RELATIVAMENTE À UNIÃO EUROPEIA

\begin{tabular}{|c|c|c|c|c|c|c|c|}
\hline & 1820 & 1870 & 1900 & 1913 & 1950 & 1973 & 1992 \\
\hline UE $-15 \ldots \ldots \ldots \ldots \ldots \ldots \ldots \ldots$ & 100 & 100 & 100 & 100 & 100 & 100 & 100 \\
\hline Portugal........................ & 64 & 55 & 49 & 40 & 47 & 65 & 68 \\
\hline Espanha........................ & 87 & 70 & 71 & 66 & 53 & 75 & 76 \\
\hline Grécia......................... & 62 & 50 & 51 & 47 & 43 & 67 & 63 \\
\hline 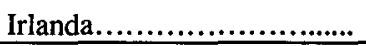 & 78 & 90 & 87 & 80 & 77 & 61 & 71 \\
\hline
\end{tabular}

Fonte: Mateus (1998): 20

Com base no quadro supra e se tivermos em conta que nos 15 países pertencentes à UE estão os países mais desenvolvidos da Europa, retiram-se imediatamente as seguintes conclusões:

1. Tendo em conta as duas datas extremas (1820-1992), Portugal chega ao início da década de 90 deste século com uma distância sensivelmente igual, relativamente aos países da EU, ou seja: 172 anos depois, anula a divergência acumulada, sobretudo na segunda metade do século XIX e primeira década deste século. Curiosamente, com um comportamento económico, neste sentido, semelhante ao da Grécia e mais favorável do que o conseguido pela Espanha, que perde 11 pontos e que a Irlanda que também se afasta 7 pontos.

2. A comparação com os países referidos permite verificar que apenas Portugal não diverge economicamente no período entre as duas Guerras; sendo claro, também, que os países, que chegaram a 1992 com um PIB per capita mais elevado, também já o detinham em 1820.

3. Os dados apresentados permitem ainda ver que, entre 1820 e 1992 , houve períodos de divergência acentuada ( 1820 - 1913, 24 pontos); convergência moderada, entre as duas guerras ( 7 pontos); convergência forte (1950 - 1973, 18 pontos) e convergência fraca (1973 - 1992, 3 pontos). É portanto, em boa parte, ao século XIX e não ao século $\mathrm{XX}$ que se devem ir procurar as razões pelo nosso atraso económico.

Apesar de algumas divergências de pormenor, os dados aqui apresentados corroboram aquilo que diversos estudos sobre o nosso crescimento económico vêm confirmando ${ }^{16}$. A segunda metade do século XIX, apesar das importantes 
modificações estruturais a nível dos transportes, das instituições, do mercado e de um crescimento positivo do PIB per capita de 0,8\% (Lains, 1995: 29), é o período em que se regista a maior divergência entre o comportamento da economia portuguesa e o das economias avançadas, «com estas a transformarem-se a um ritmo marcadamente superior, em contraste flagrante com o que viria a acontecer depois» (Reis, 1993: 6).

Temos então que, se o século XIX foi de forte divergência, o mesmo não aconteceu com o século XX: «A economia portuguesa registou, no período de 1910 a 1996, uma taxa de crescimento média anual do PIB de 3,5\%, passando de uma capitação anual de 159 para 1715 contos, a preços de 1997 , ou, em dólares correntes, de 920 dólares por pessoa para cerca de 10 mil. $\mathrm{O}$ rendimento per capita cresceu, ao longo do período, cerca de $2,8 \%$ ao ano» (Mateus, 1998: 17). Este comportamento positivo da nossa economia, durante o século XX, permitiu reduzir o fosso, em relação aos países hoje integrados na UE, como já vimos, em cerca de 28 pontos percentuais, ainda que grande parte dessa redução tivesse ocorrido nas últimas três décadas. Pode assim dizer-se que, tendo por base o PIB per capita, de nenhum período posterior à Primeira Guerra Mundial se deve falar em perda de velocidade, relativamente às economias mais adiantadas. A década de 20 marca mesmo a fase em que, segundo César das Neves (1991: 819), o «equilíbrio de pobreza» do nosso desenvolvimento teria sido quebrado, ainda que só mais tarde (década de 50) Portugal tivesse entrado naquilo que normalmente se denomina de crescimento sustentado.

Esta perspectiva sobre a economia portuguesa fica ainda mais clara se seguirmos de perto a periodização sobre o crescimento económico no século XX, recentemente avançada por Abel Mateus (1998: 21).

- Fase 1 (1910-1926): período dominado por fortes desequilíbrios macroeconómicos, acentuados por uma elevada taxa de inflação (a maior do século). A taxa de crescimento do PIB atingiu o 1,36\%, e a do PIB per capita apenas $0,8 \%$, performance mesmo assim não inferior à dos países desenvolvidos da Europa, que registaram, em igual período, um crescimento médio do PIB de apenas $0,8 \%$.

- Fase 2 (1926-1950): período atravessado por importantes transformações políticas e económicas, como o derrube da I República e instauração da Ditadura, pelos impactos da grande depressão (1929-1934), pela edificação do Estado Novo (1932-1933) e pelas consequências da Segunda Guerra Mundial, acabou por ficar marcado por um crescimento económico lento, mas que acabaria por criar as pré-condições para o crescimento sustentado das décadas seguintes ${ }^{17}$. Durante esta fase, pode dizer-se que a estrutura produtiva do nosso país se manteve constante, crescendo o PIB, entre 1928 e 1938, a uma taxa média de 2,4\% ao ano; 
resultado que não permite afirmar que a década de trinta tivesse sido de estagnação;

- Fase 3 (1950-1974): parece haver unanimidade em todos os investigadores deste período: trata-se de uma época de ouro em termos de crescimento da economia portuguesa. Para tanto, avançam-se números nunca registados: entre 1953 e 1973, o crescimento económico atingiu uma taxa média anual de 5,6\% do PIB per capita. E, apesar deste período ser também de ouro para o crescimento mundial (o PIB per capita a nível mundial cresceu, em média, $2,9 \%$ ao ano, mais do que três vezes o que havia sucedido entre 1913-1950), apesar disso, dizíamos, a economia portuguesa convergiu, neste período, cerca de 18 pontos percentuais $(65 \%$ da média da UE). Lembra Abel Mateus (1998: 99), que temos vindo a seguir neste resumo, que para este crescimento e convergência foram determinantes o progresso técnico, o capital físico e, com menor destaque, o capital humano, bem como noutro registo a abertura da nossa economia ao exterior (recorde-se que a nossa entrada na EFTA se deu em 1960).

- Fase 4 (1974-1984), o período que se seguiu ao 25 de Abril, se foi rico em conquistas importantes, como a liberdade, a democracia e outros direitos políticos e sociais, o mesmo não se poderá dizer em termos de crescimento económico: entre 1975 e 1984, muito também por causa dos choques petrolíferos, assistiu-se a quebras sucessivas do PIB, interrompendo um período longo de convergência com os países que actualmente compõem a UE, alargando-se o fosso que nos separava, em 5 pontos percentuais. Ainda assim, com a integração de Portugal na CEE, em 1986, o país ganha nova dinâmica económica e entra em novo processo de convergência, podendo dizer-se que, entre 1984 e 1997, o país diminui em cerca de 22 pontos percentuais o fosso que o separa da Europa dos 15 , ritmo sem precedentes na história económica portuguesa.

Não obstante, e apesar deste resultado francamente favorável na riqueza criada, Portugal não conseguiu eliminar um atraso acumulado de décadas, a nível da distribuição da riqueza: «Nos finais dos anos 80 Portugal era o país da UE com a taxa de pobreza mais elevada, afectando $26,5 \%$ da população ...» (Mateus, 1998: 160). Persistem também as gritantes disparidades regionais acumuladas, tanto a nível dos rendimentos dos agregados familiares ${ }^{18}$, como do PIB per capita ${ }^{19}$. É certo que, como têm salientado alguns autores (Gaspar, 1987: 118), as desigualdades entre as regiões tendem a estreitar-se; é verdade também que os dualismos da sociedade portuguesa, de que falava Sedas Nunes (1964), são hoje diferentes; todavia, agravam-se dia-a-dia dois fenómenos novos: por um lado, aumentam os casos de exclusão social e muito por causa do processo de litoralização e despovoamento do interior; por outro, 
cresce a tendência para $o$ aumento das desigualdades intra-regionais, dificilmente detectadas nos cálculos de PIB per capita por distritos. Lembra Jorge Gaspar (1987: 118) que «existe, a vários títulos, maior identidade entre os centros urbanos do interior e do litoral, do Alentejo e do Minho ou de Trás-os-Montes, que entre esses centros e as áreas mais recônditas das respectivas regiões em que se inserem», prova cabal de que as desigualdades intra-regionais se mantêm activas, «não só no que concerne à oposição urbano/rural, mas também relativamente ao interior do território rural».

\section{ATRASO ECONÓMICO OU ARRANQUE TARDIO?}

Analisadas as várias fases do nosso crescimento económico e os períodos em que divergimos/convergimos, relativamente aos países mais desenvolvidos, é tempo de responder à questão formulada anteriormente na alínea b): caso fossem outras as políticas seguidas, Portugal poderia ter tido um comportamento económico melhor do que aquele que acabámos de acompanhar?

Pode dizer-se que a resposta a esta questão tem sido, até pelas implicações teóricas, metodológicas e mesmo ideológicas que envolve, a principal razão para a falta de consenso na nossa historiografia sobre a explicação do nosso atraso económico. É verdade que os recentes estudos comparativos, baseados na quantificação da actividade económica, trouxeram novas perspectivas de abordagem e mostraram claramente quando e como ficámos pelo caminho. No entanto, os resultados conseguidos continuam a não ser conclusivos na explicação que ainda hoje divide alguns autores: porque razão ficámos para trás e o que nos levou a descolar mais tarde que os outros? Simplificando e utilizando uma análise extremamente redutora desta importante problemática, que obviamente deixa de fora posições mais heterodoxas e, porventura, não menos importantes, podemos dizer que a investigação sobre a magna questão do nosso atraso económico se tem escorado em duas correntes de pensamento, que procuram responder-lhe tendo subjacente teorias diametralmente opostas:

a) De um lado, perfilam-se todos os investigadores que, acentuando mais uma ou outra vertente, partem do princípio de que era possível, caso fossem outras as políticas (e aqui inserem-se temas como proteccionismo/livre-cambismo, papel de Portugal na economia-mundo, crescimento/desenvolvimento, papel das forças sociais, modernidade/tradição, etc.), evitar o nosso atraso económico. De uma maneira ou de outra, a esta concepção estão ligados nomes, com gradações diferentes e explicações múltiplas, como Antero de Quental, Oliveira Martins, Basílio Teles, Antonio 
Sérgio e, mais recentemente, Vitorino Magalhães Godinho, Joel Serrão, Miriam Halpern Pereira, para apenas citarmos os mais representativos. A todos pareceu inquestionável que Portugal, apesar de todas as limitações inerentes a um país pequeno e geograficamente periférico, caso tivessem sido outros o caminhos seguidos, poderia ter evitado chegar ao século XX na cauda da Europa. De forma simplificada, podemos resumir assim os principais contributos desta corrente: na primeira linha das críticas às políticas seguidas, em vários momentos da nossa história, aparece a persistente dependência externa do país face à Inglaterra, que teria contribuído para que o nosso país fosse levado a especializar-se na produção de produtos primários, em claro detrimento da indústria, sabidamente mais favorável à modernização e crescimento da economia e à criação de um maior valor acrescentado ${ }^{20}$; critica-se, também, a falta de coragem política para acabar com uma estrutura fundiária vinda do Antigo Regime, de que resultou uma excessiva concentração da propriedade nas mãos dos latifundiários do Sul, a par de uma excessiva fragmentação e dispersão da propriedade camponesa no Norte, realidade económica com consequências nefastas na criação de um mercado interno qualitativa e quantitativamente mais rico, capaz de permitir uma mais intensiva acumulação de capital para o necessário investimento; critica-se, ainda, o facto de Portugal não ter criado as condições políticas e sociais que permitissem a transformação de estruturas sociais e mentais abertas à modernidade, espartilho que impediu as necessárias transformações de sectores como a agricultura, indústria e transportes ${ }^{21}$. Concomitante com esta situação uma burguesia com hábitos nobiliárquicos anacrónicos, mais interessada em comprar terras, títulos, do que em investir nos novos sectores, como era o caso da indústria ${ }^{22}$.

b) No extremo oposto a esta explicação, perfilou-se, mais recentemente, uma outra corrente historiográfica que, desenvolvendo os seus estudos mais de acordo com as teorias e metodologias da Nova História Económica, tem vindo a defender que o crescimento económico português, nomeadamente durante o século XIX, período em que mais divergimos, esteve muito próximo do seu potencial máximo.

Nos trabalhos realizados por esta corrente, está sempre subjacente a ideia de que os países mais ricos outra coisa não fizeram do que 
desenvolver um potencial económico relativamente mais elevado já na fase de arranque. Com isto pretende-se, no essencial, dizer o seguinte: o atraso económico do nosso país era como que inevitável, à luz da comparação com o potencial económico de outras economias. A este propósito, Jaime Reis (1993: 30-31), num estudo considerado marcante para a afirmação desta corrente, escreveu: «em 1900, Portugal estava afundado no atraso económico, dificilmente a situação poderia ter sido outra. Isto pode parecer banal, mas, na realidade, penso que o não $e_{\text {». Antes }}$ de mais, acrescenta o mesmo autor, "porque vai contra a corrente da nossa historiografia, que sugere que outra evolução era então possível» (Reis, 1993: 31). Como é fácil de ver, esta nova forma de encarar o nosso processo de desenvolvimento, não só recusa explicitamente o modelo de explicação do nosso atraso económico, até há pouco dominante, como pretende deixar claro que, para compreender o nosso fracasso económico, é necessário ter em consideraçấo o real potencial económico de Portugal: recursos naturais, configuração dos mercados externos, a tecnologia disponível, o "stock" de capital humano, etc. Investigações realizadas neste domínio revelaram, utilizando nomeadamente o contrafactual (Reis, 1993), que o potencial económico do nosso país, mesmo que elevado ao máximo, dificilmente teria evitado a entrada tardia de Portugal no denominado crescimento económico moderno. Foram ainda estes mesmos princípios que conduziram o recente estudo de Pedro Lains (1995) e que lhe permitiram concluir, ainda que suavizando algum do fatalismo inscrito nos trabalhos de Jaime Reis, o seguinte: «tal não significa que Portugal estivesse condenado a um crescimento mais lento, mas apenas que, se o crescimento económico do país, entre 1870-1913, tivesse sido mais intenso do que aquele que se verificou, isso deveria ser visto como um caso de êxito excepcional no contexto dos países europeus» (Lains, 1995: 34).

As divergências entre as duas correntes não deixam dúvidas, sendo talvez ainda cedo para que se possam tirar conclusões definitivas. $O$ debate continua vivo e uma conclusão parece, para já, poder retirar-se: um melhor conhecimento do nosso processo de desenvolvimento económico, designadamente sobre a segunda metade do século XIX, e a clara percepção do nosso crescimento sustentado, depois de 1950 , tornaram possível um novo olhar sobre o comportamento económico do nosso país: à perspectiva da 
decadência que se seguiu ao século XVI e à centralização do olhar sobre o nosso atraso, relativamente às principais potências, talvez seja preferível uma abordagem do problema focalizada naquilo que parece ter sido afinal uma descolagem tardia. De facto, como referem Mata e Valério (1994: 240), «torna-se inútil discutir as possibilidades de um país com o tamanho de Portugal manter a posição hegemónica no comércio intercontinental que deteve por algum tempo nos séculos XV e XVI; e não mais é possível argumentar que Portugal está condenado a ficar na cauda das economias do mundo ou mesmo da Europa no que respeita ao desenvolvimento económico».

Por outro lado, resulta também claro que a complexidade da realidade portuguesa não parece favorecer os amantes de generalizações. Apenas alguns exemplos: durante os séculos XIX e XX, períodos houve que políticas económicas aparentemente boas falharam (as politicas proteccionistas, por exemplo) e decisões reconhecidamente más (caso do condicionamento industrial) que, ainda assim, não impediram o crescimento económico. Este princípio, que recomenda prudência às generalizações, talvez também se aplique aos que, com base em teorias económicas liberais e na história económica portuguesa (sobretudo quando se verifica que, no século $\mathrm{XX}$, o desempenho da nossa economia foi melhor nas fases em que mais se abriu ao intercầmbio internacional do que quando se fechou e/ou se protegeu), desvalorizam as influências da economia-mundo. Ninguém acredita, queremos crer, que a integração internacional e os choques económicos daí resultantes tenham apenas efeitos positivos. Todos sabemos como tem sido grande a capacidade da economia-mundo, de molde a condicionar o desenvolvimento dos povos, ao longo da história. A ser assim, a recusa das teses, que centravam a explicação do nosso atraso na dependência, não pode dar lugar a explicações que só vêem factores positivos na abertura da nọssa economia. $O$ aprofundamento dos estudos sobre esta problemática mostrará, estamos certos, que a integração inevitável na economia-mundo teve aspectos positivos e negativos e que na escolha política de cada momento talvez resida a chave para não aceitarmos, nem o fatalismo, nem o impossível.

\section{CONCLUSÃO}

Terminamos mais ou menos como começámos: tínhamos como objectivo principal dialogar, confrontar leituras, que entretanto se foram fazendo, sobre - nosso processo de modernização económica. Foi isso que fizemos, 
utilizando a liberdade de selecção que, normalmente, cabe a quem dialoga. $\mathrm{E}$, se há alguma conclusão a retirar, deste confronto de ideias em torno do nosso processo de modernização, ela passa pela convicção de que esta problemática, apesar de nunca deixar de ser central, está mais viva do que nunca, tanto no seio da comunidade científica, como na sociedade portuguesa.

Por outro lado, penso ter ficado também mais ou menos claro que os conhecimentos actuais sobre o nosso desenvolvimento, sobretudo quando enquadrados no contexto internacional, tornam inviável a continuação persistente de leituras globalmente decadentistas. Do mesmo modo, acabam por condicionar todas e quaisquer concepções mais ou menos deslumbradas acerca do nosso desenvolvimento que, não raro, tendem a confundir estar com o centro da economia-mundo, com estar no centro.

Não há dúvidas sobre isso, todos os indicadores socioeconómicos convergem, em relação à nossa posição no sistema mundial: somos um país semiperiférico, com um importante papel de intermediação no contexto da economia-mundo. Economia, portanto, de desenvolvimento intermédio, caracterizada pela coexistência de diferentes níveis de desenvolvimento. A consciência da nossa realidade social, ou como gostam de referir alguns autores, a transformação deste conhecimento em senso comum, talvez se apresente hoje como a melhor forma, não só de aprofundarmos o conhecimento sobre nós mesmos, naquilo que afinal marca a nossa singularidade, mas também de contribuirmos para eliminarmos de vez um processo de modernização inacabada, com indicadores sociais contraditórios.

\section{NOTAS}

* O trabalho que ora se publica, ampliado e anotado, resulta de uma conferência proferida em Seia (10-11-1999), no âmbito das II Jornadas Históricas, O Século XX e o Final do Milénio.

${ }^{1}$ Boaventura Sousa Santos, «Onze Teses por ocasião de mais uma descoberta de Portugal», Via Latina, 1991 (Publicação não periódica), p. 63.

2 Escreveu a este propósito Miriam Halpern Pereira (1991: 6), referindo-se, em particular, à historiografia: «... ○ Estado Novo provocou uma profunda asfixia da investigação científica no domínio da história». Veja-se, neste mesmo sentido, António Rafael Amaro, «Alberto Sampaio e a historiografia Portuguesa», Revista Portuguesa de História, Tomo XXX, 1995, p. 167-173; João Paulo Avelãs Nunes, A História Económica e Social na Faculdade de Letras da Universidade de Coimbra, 1911-1974, Lisboa, Instituto de Inovação Educacional, 1995.

${ }^{3}$ B. Sousa Santos, art. cit., p. 58. 
4 José Manuel Leite Viegas e Antonio Firmino da Costa, «Introdução», Portugal, que Modernidade?, Lisboa, Celta Editora, 1998, p. 3.

${ }^{5}$ Idem, ibidem, p. 1 .

${ }^{6}$ Boaventura de Sousa Santos, art. cit, p. 59

7 Félix Ortega, El mito de la modernización: las paradojas del cambio social, Barcelona, Editorial Anthropos, 1994, p. 16 (tradução nossa).

${ }^{8}$ A primeira formulação do conceito de semiperiferia que aqui utilizamos foi feita por Immanuel Wallerstein na obra The Modern World-System, Nova Iorque, Academic Press, 1974 (Trad. Portuguesa: o Sistema Mundial Moderno, Porto, Edições Afrontamento, 1990).

${ }^{9}$ Vejam-se, entre outros, os trabalhos interdisciplinares sobre a sociedade portuguesa publicados em Portugal: um retrato singular (Org. Boaventura Sousa Santos), Porto, Ediçōes Afrontamento, 1993.

${ }^{10}$ Veja-se, a este propósito, José Reis (1993: 141): «O conceito de semiperiferia assenta em duas bases fundamentais: a da intermediação política e a da combinação de estatutos sócio-económicos. A primeira tem a ver com as relações político-estratégicas mundiais e traduz-se na indispensabilidade estrutural da semiperiferia para amortecer as tensões que se produziriam no relacionamento directo entre as categorias polares. A segunda é de sede mais especificamente económica e procura reflectir a circunstância de tais sociedades disporem, quer da produção de bens primários destinados à exportação, quer de uma estruturação económica interna que consolidou a produção de bens manufacturados para o seu mercado interno. Uma posição que é, ao mesmo tempo, de subordinação e de autonomia».

${ }^{11}$ Referindo-se a esta característica estruturante na sociedade portuguesa, escreveu B. Sousa Santos (1991: 62): "Talvez resida aqui o "mistério" da coexistência no homem português do complexo de inferioridade perante os estrangeiros ao lado de uma hipertrofia mítica gerando megalomanias e quimeras».

12 Saliente-se que o autor, citando o Dicionário de Fernando J. da Silva, define o conceito de disfunção como "perturbação do funcionamento de um órgão ou aparelho", para concluir: «É esse justamente o caso de Portugal em termos do sistema internacional: o de um órgão com funcionamento perturbado, anómalo e dificil de entender» (Telo, 1997: 653).

${ }^{13}$ Na opinião de B. Sousa Santos (1993: 20), «Portugal é uma sociedade semiperiférica da região europeia do sistema mundial. Durante vários séculos essa posição semiperiférica assentou no império colonial português. A partir do seu desmantelamento, em 1974, Portugal tem vindo a renegociar a sua posição no sistema mundial. Tudo indica que essa posição semiperiférica vai manter-se, desta vez devido à integração na CEE e às relações económicas e sociais privilegiadas com a África lusófona».

${ }^{14}$ Para uma comparação mais minuciosa, cf. Relatório do Desenvolvimento Humano, 1998 (Publicado para o Programa das Nações Unidas para o Desenvolvimento), Lisboa, Trinova Editora, 1998. 
15 Veja-se, a este propósito, Pedro Hespanha (1993: 285): «Quando se analisa a reprodução social do ponto de vista dos consumos ou dos rendimentos que os suportam, verifica-se que uma parte significativa desses rendimentos é sistematicamente gerada fora das estruturas formais da economia capitalista e que, por outro lado, uma parte também significativa dos consumos é satisfeita fora do mercado, em regime de auto-produção ou de troca directa e, portanto, independentemente da existência de rendimentos monetários». Isto «implica, entre outras coisas, um peso relativo elevado dos rendimentos não capitalistas no rendimento disponível das famílias e uma incidência igualmente elevada de trocas nãomercantis de bens e serviços. $\mathrm{O}$ primeiro fenómeno reside em grande medida na pequena agricultura familiar e nas funções materiais e simbólicas que ela comporta. $\mathrm{O}$ segundo fenómeno reside no que designamos por sociedade-providência».

${ }^{16}$ Apesar de um relativo acordo quanto ao crescimento da economia portuguesa para período de 1850-1913 (0,8\%), avançado pela primeira vez por David Justino (1987: 459), o mesmo parece não acontecer para a medição das flutuações sobre o mesmo período: Nunes, Mata e Valério (1989: 292-293) defendem que, entre 1850-1890, houve um crescimento positivo mais acelerado, quedando-se o período que medeia entre 1890 e 1913 por uma quase estagnação. Já os cálculos efectuados por Pedro Lains e Jaime Reis «defendem que o produto cresceu menos entre 1850-1870, seguindo-se um período de crescimento a taxas mais baixas mas que se estendeu até 1900, estagnando desde então» (Lains, 1995: 29).

${ }^{17}$ Cf. Abel Mateus, Economia Portuguesa desde 1910, Lisboa, Editorial Verbo, 1998, p. 47.

18 Cf. Maria Emília Castanheira e Maria Filomena Carvalho, «Desigualdade na distribuição do rendimento e disparidades regionais», Prospectiva e Planeamento, 3/4 (1997-1998), p. 267-277.

19 Cf. Pedro Nogueira Ramos, «Estão os desequilibrios regionais a aumentar em Portugal», Notas Económicas, n¹2, 1999. Observa este autor que muito embora os distritos do interior tenham visto diminuir levemente o seu atraso relativo em relação aos distritos do litoral (entre 1990-1995), continuando, no entanto, Lisboa a ganhar para o resto do país, «é também verdade que são ainda graves e profundos os desequilíbrios regionais que subsistem em Portugal - isto é, as diferenças de níveis entre PIB per capita dos diferentes distritos portugueses». Só um exemplo: o distrito de Lisboa tinha em 1994 um PIB per capita cerca de 3 vezes superior ( $154,7 \%$ da média nacional) ao de Viseu, com apenas 58,4 $\%$.

${ }^{20}$ Veja-se, entre outros, Miriam Halpern Pereira, Livre-Câmbio e Desenvolvimento Económico: Portugal na Segunda Metade do Século XIX, Lisboa, Cosmos, 1971.

${ }^{21}$ Idem, ibidem.

${ }^{22}$ Neste sentido, ver entre outros, Vitorino Magalhães Godinho, A Estrutura da Antiga Sociedade Portuguesa, Lisboa, Horizonte, 1971, cap. 4; Joel. Serrão e Gabriela Martins, Da Indústria Portuguesa: do Antigo Regime ao Capitalismo, Lisboa, Horizonte, 1978. 
Contributos para uma reflexão sobre algumas leituras do processo de modernização da sociedade portuguesa contemporânea

\section{BIBLIOGRAFIA}

AMARAL, Luciano (1998), «Convergência e crescimento económico em Portugal no pósguerra», Análise Social, Vol. XXXIII (148), Lisboa, p. 741-776.

AMARO, António Rafael (1995), Alberto Sampaio e a Historiografia Portuguesa Contemporânea (Separata da Revista Portuguesa de História), Tomo XXX, Coimbra.

BARRETO, António (1996), A Situação Social em Portugal, 1960-1995, Lisboa, Instituto de Ciências Sociais - Universidade de Lisboa.

FORTUNA, Carlos (1993), «O Desenvolvimento por um Fio: Portugal Colonial, os Têxteis de Algodão e a Economia-Mundo», in Portugal: Um Retrato Singular, Porto, Edições Afrontamento.

GASPAR, Jorge (1987), Portugal, Os Próximos 20 Anos: Ocupação e Organização do Espaço-Retrospectivas e Tendências, Lisboa, Fundação Calouste Gulbenkian.

GODINHO, Vitorino Magalhães (1971), A Estrutura da Antiga Sociedade Portuguesa, Lisboa, Horizonte.

HESPANHA, Pedro (1993), «Das Palavras aos Actos. Para uma Elegia do Amor Camponês à Terra", in Portugal: Um Retrato Singular, Porto, Edições Afrontamento.

JUSTINO, David (1987), «A evolução do produto nacional bruto em Portugal, 1850-1910 algumas estimativas», Análise Social, Vol. XXIII (97), Lisboa, p. 451-461.

LAINS; Pedro, A Economia Portuguesa no Século XIX, Lisboa, Imprensa Nacional Casa da Moeda.

MACHADO, Fernando Luís, COSTA, António Firmino, «Processos de uma Modernidade Inacabada», in Portugal, Que Modernidade?, Oeiras, Celta Editora.

MATA, Eugénia; VALÉRIO (1993), História Económica de Portugal - Uma Perspectiva Global, Lisboa, Editorial Presença.

MATEUS; Abel (1998), Economia Portuguesa desde 1910, Lisboa, Editorial Verbo.

NEVES, João César (1991), «O desenvolvimento económico português e o padrão transversal de crescimento, 1833-1985», Análise Social, Vol. XXVI (112-113), p. 807-822.

NUNES, A. Sedas (1964), «Portugal, sociedade dualista em evolução», Análise Social, Vol. II, (7-8), Lisboa, p. 407-461.

NUNES, Ana Bela; MATA, Eugénia; VALÉRIO, Nuno (1989), «Portuguese Economic Growth, 1833-1985», Journal of European Economic History, Vol. 18, n 2, p. 291330.

NUNES; João Paulo Avelãs (1995), História Económica e Social na Faculdade de Letras da Universidade de Coimbra, Lisboa, Instituto de Inovação Educacional.

ORTEGA, Félix (1994), El Mito de la Modernización: Las Paradojas del cambio social, Barcelona, Anthropos.

PEREIRA, Miriam Halpern (1971), Livre-Câmbio e Desenvolvimento Económico: Portugal na Segunda Metade do Século XIX, Lisboa, Cosmos. 
PORTELA, José (1994), Agriculture is Primarily What?, in Agricultural Restructuring and Rural Change In Europe, Agricultural University - Wageningen.

PORTELA, José (98), «Um olhar diferente sobre a agricultura», Vida Rural, n 1643, Lisboa, p. 6-7.

RAMOS, Pedro Nogueira (1999), «Estão os desequilíbrios regionais a aumentar em Portugal», Notas Económicas, $\mathrm{n}^{\circ} 12$.

REIS, Jaime (1993), O Atraso Económico Português em Perspectiva Histórica (1850-1930), Lisboa, Imprensa Nacional Casa da Moeda.

REIS; José (1993), «Portugal: A Heterogeneidade de uma Economia Semiperiférica», in Portugal: Um Retrato Singular, Porto, Edições Afrontamento.

Relatório do Desenvolvimento Humano (1998), Lisboa, Programa das Nações Unidas para o Desenvolvimento, Trinova Editora.

SANTOS, Boaventura Sousa (1991), «Onze Teses por ocasião de mais uma descoberta de Portugal», Via Latina, (Publicação não periódica), p. 58-64.

SANTOS, Boaventura Sousa (1993), «O Estado, as Relações Salariais e o Bem-Estar Social na Semiperiferia», in Portugal: Um Retrato Singular, Porto, Edições Afrontamento.

SANTOS, Boaventura Sousa (org. 1993), Portugal: Um Retrato Singular, Porto, Edições Afrontamento.

SERRÃO, Joel; MARTINS, Gabriela (1978), Da Indústria Portuguesa: Do Antigo Regime ao Capitalismo, Lisboa, Horizonte.

TELO; António José, «Treze teses sobre a disfunção nacional - Portugal no sistema internacional», Análise Social, Vol. XXXII (142), Lisboa, p. 649-683.

VIEGAS, José Manuel Leite; COSTA, António Firmino da (1993), «Introdução», in Portugal, Que Modernidade?, Oeiras, Celta Editora.

VIEGAS, José Manuel Leite; COSTA, António Firmino da (Org. 1998), Portugal, Que Modernidade?, Oeiras, Celta Editora.

WALLERSṬEIN, Immanuel (1990), O Sistema Mundial Moderno, Porto, Edições Afrontamento. 